\title{
Rotor side Control of High Power Slip Ring Induction Motor using a Single Thyristor
}

\author{
V. V. Maruthi Prasad ${ }^{1}$, W. Prasanna Narasimham ${ }^{2}$, G. Sai Raghu Ram ${ }^{3}$ \\ '( Electrical \&Electronics Engg. Dept., JNTU Hyderabad, India.) \\ ${ }^{2}$ (Electrical \&Electronics Engg. Dept., Osmania University Hyderabad, India.) \\ 3 ( Electrical \&Electronics Engg. Dept., Osmania University Hyderabad, India.)
}

\begin{abstract}
The aim is to create a Simple control mechanism for speed variations of a HIGH POWER SRIM Slip Ring Induction motor as an extension to the available Non slip power recovery mechanisms available for low power SRIMs. The most basic ways to control the speed of a slip ring induction motor is either from the STATOR OR ROTOR SIDE. The mechanism employed here is to control the speed via a Single thyristor acting as an ON/OFF switch at the rotor side of this slip ring induction motor. The core scheme here is to control the high power machine by directly varying the load current or the rotor side current by the single thyristor after conversion of the available load side current into the DC current by a 3 phase RECTIFIER BRIDGE made of 6 diodes respectively. Thus, all the AC power is converted into simple DC current and is controlled by the thyristor ON/OFF time giving the required speed control as the rotor current is directly proportional to speed and torque in an increasing power scenario as in this case. Even the losses due to non-slip power recovery can be considerably neglected because of the machines high power status. Thus, we are able to simply control a high power SRIM by just varying the amount of ON/OFF time of the thyristor at the rotor end efficiently.

Thus, this method is best suited for very high inertia loads, which requires a pull-out torque at almost zero speed and accelerate to full speed with minimum current drawn in a very short time period.
\end{abstract}

Key Words: Thyristor, Slip Ring Induction Motor (SRIM), Stator and Rotor, Polyphase motor, Universal Bridge.

\section{Introduction}

A closed-loop control system for an ordinary wound rotor induction motor makes use of thyristors in the secondary side as pulse width modulated dc switch operating at a suitable preset pulse repetition rate. The slip frequency rotor voltage is rectified and fed to a thyristor chopper, a variable ON time of which results in a variable speed. The ON time is controlled by a strong feedback loop from speed signals, so that the set speed remains nearly constant irrespective of load variations. It is observed that torque of the machine varies widely with ON time depending on the two possible extreme conditions: 1) when the thyristor switch is in parallel with the source (rectified rotor voltage) and external resistance; and 2) when the switch is in series with the source and external resistance. The scheme may be adopted as a brushless drive system. The whole schema runs good with the Chopper type control and is mostly essential and suitable to the low power class of motors. With considerable increase in the power ratings of the motors being used, we need to modify the system to meet the current demand on the rotor side and this is not possible with the IGBTs which have a very limited range of ratings and even if taken, the manufacturing of IGBT will cost more than the entire system. So, it is very irrevocable to use standard thyristors which give us a better current withstanding and proper output with decent switching speeds [13].

Thus, we modify the construction of the present mechanism by exclusively designing a rotor side speed control drive which serves as a basis for the high power slip ring induction motors rotor side control. This is thus achieved by a single thyristor controlling the entire flow of rotor current suitably converted at the DC end being in parallel with the load resistance. This new and unused mechanism of speed control provides us the simplest technique of controlling the entire scheme via the turn on and turn off of the single load side thyristor and gives us the much required high current tolerance which is not possible and if possible is not economically viable. This forms the brief introduction to the entire project analysis and motive and thus gives us a peep through to the entire project and the procedure involved and the desired result to be expected as the outcome of the project done.

Speed control of SRIM can be done majorly by two schemes :

1. Stator side control

2. Rotor side control

a. Slip power recovery mechanisms

b. Non slip power recovery mechanisms 
This scheme is a good example of the Non-slip power recovery mechanism. This does not involve the power from on rotor side be fed back to the source. This mechanism may be a bit lossy but proves to be an effective cheap way of achieving speed control where losses are admissible.

\section{Effect Of Adding External Resistance}

Adding external resistance to the rotor of a slip ring induction motor, makes the rotor resistance high during starting, thus the rotor current is low and the starting torque is maximum. Also, the slip necessary to generate maximum torque is directly proportional to the rotor resistance. In slip ring motors, the rotor resistance is increased by adding external resistance. If the rotor resistance is high, the slip is more, thus it's possible to achieve "pull-out" torque even at low speeds. When the motor reaches its base speed (full rated speed), as the external resistance is removed and under normal running conditions, it behaves in the same way as a squirrel cage induction motor.

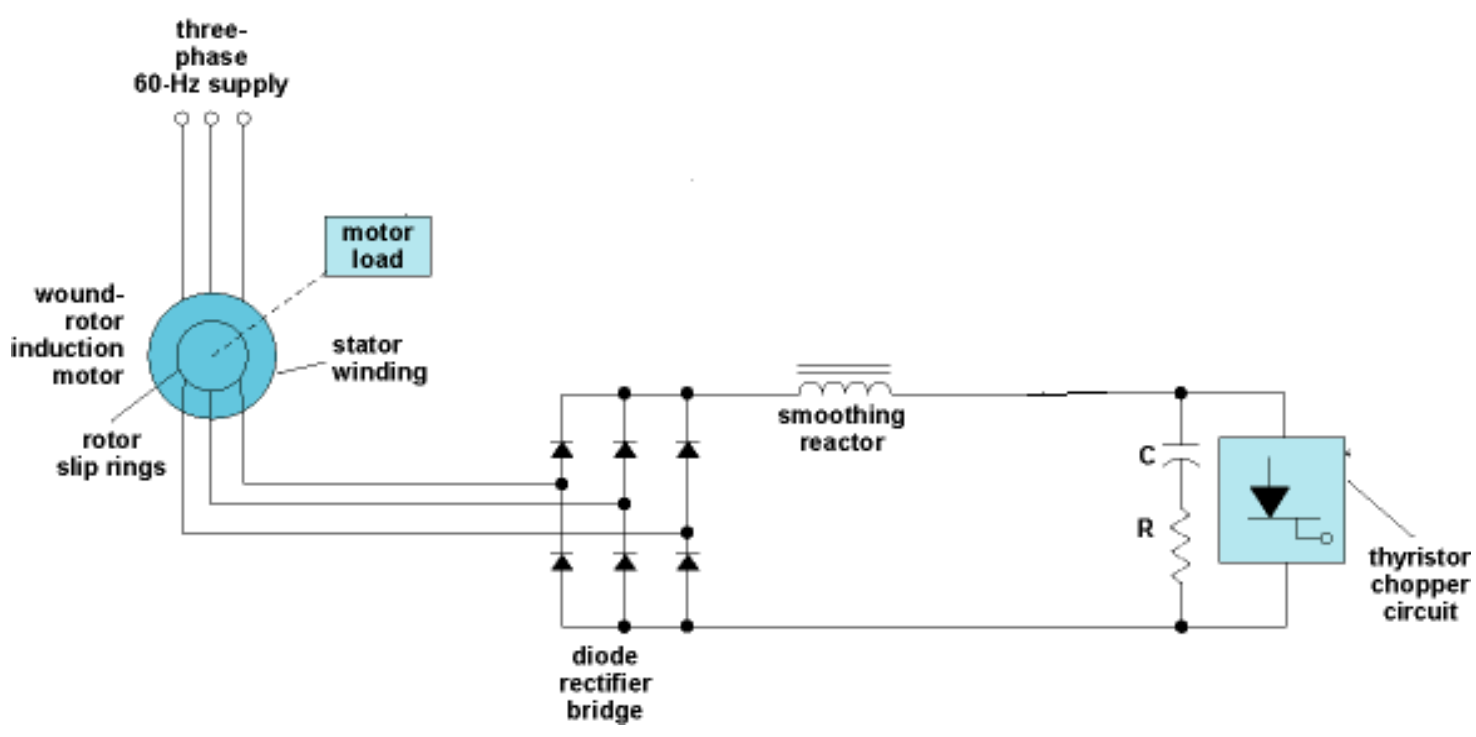

Fig : Circuit for Static Rotor Resistance control

\section{Starting And Speed Control Of SRIM}

A single phase induction motor is not self-starting. Thus, it is necessary to provide a starting circuit and associated start windings to give the initial rotation in a single phase induction motor. The normal running windings within such a motor can cause the rotor to turn in either direction, so the starting circuit determines the operating direction. The four methods of starting an induction motor are direct on-line, reactor, auto-transformer and star-delta. Unlike a wound-rotor motor, the rotor circuit is inaccessible and it is not feasible to introduce additional resistance for starting or speed control. For small single-phase shaded-pole motor of a few watts, starting is done by a shaded pole, with a turn of copper wire around part of the pole. The current induced in this turn lags behind the supply current, creating a delayed magnetic field around the shaded part of the pole face. This imparts sufficient rotational character to start the motor. These motors are typically used in applications such as desk fans and record players, as the starting torque is very low and low efficiency is not objectionable.

Larger single phase motors have a second stator winding fed with out-of-phase current; such currents may be created by feeding the winding through a capacitor or having it have different values of inductance and resistance from the main winding. In some designs, the second winding is disconnected once the motor is up to speed, usually either by a centrifugal switch acting on weights on the motor shaft or a thermistor which heats up and increases its resistance, reducing the current through the second winding to an insignificant level. Other designs keep the second winding on when running, improving torque. Polyphase motors have rotor bars shaped to give different speed/torque characteristics. The current distribution within the rotor bars varies depending on the frequency of the inducted current. At standstill, the rotor current is the same frequency as the stator current, and tends to travel at the outermost parts of the squirrel-cage rotor bars. As the rotor accelerates, the slip frequency declines, and current tends to travel deeper within the squirrel cage bars. Polyphase motors can generate torque from standstill, so no extra mechanism is required to initiate rotation. The different bar shapes can give usefully different speed/torque characteristics as well as some control over the inrush current at startup. 
In a wound rotor motor, slip rings are provided and external resistance can be inserted in the rotor circuit, allowing the speed/torque characteristic to be changed for purposes of acceleration control and speed control.

\section{What happens if SRIM is started as a normal induction motor?}

If SRIM is started with all the slip rings(i.e. the rotor terminals) shorted, like a normal induction motor, then it suffers extremely high locked rotor current, ranging up to $1400 \%$, accompanied with very low locked rotor torque as low as $60 \%$. So, it is not advised to start a slip ring induction motor with its rotor terminals shorted [12].

\section{Simulink Circuit}

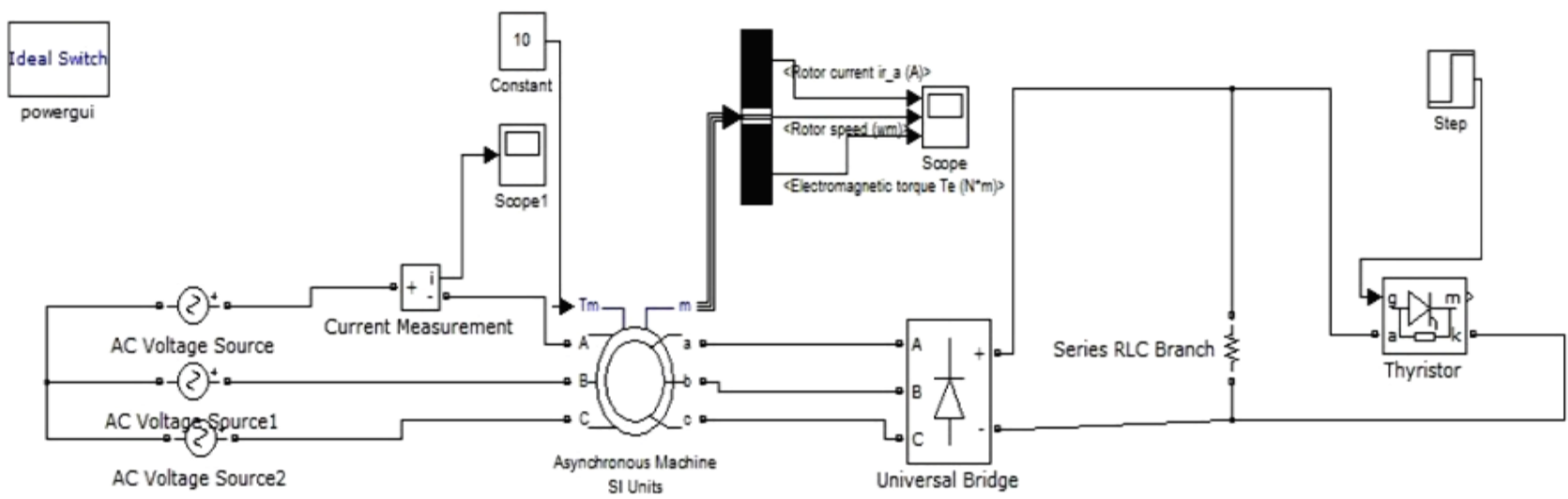

Fig: SIMULINK circuit for single thyristor control

The circuit basically involves a $3 \phi$ AC supply fed $3 \phi$ asynchronous induction machine i.e. slip ring induction motor also called as the wound rotor induction motor here in this case. The output is fed to the Bus selector which acts as a multiplexer giving us a wide range of output measurements essential to analyze the circuit and the outputs are graphically observed by the scope which provides us the detailed view of the measured output values such as torque, current and speed.

A simple R - load is used for the analysis of the output of SRIM. To this load, for obtaining the desired speed control we establish a thyristor of considerable value in parallel acting as a load manipulator giving us thus the essential control over the motor by drop down rotor current control of the machine. We leave the Tm open as we want the asynchronous machine to work as the motor which if given will make the machine run as an Induction generator. To suitably manipulate the thyristor triggering, a step signal is used at the GATE terminal of the thyristor so that a simple ON/ OFF control of the device is possible and a simpler control is expected. A wide range of other triggers depending on the desired characteristics can be chosen[11].

\section{Output Plots \& Analysis}

Upon analysis of the output we can have the following results as interpreted from the SIMULATION.

Basic speed of the machine rotor is 1498.93 RPM. (Synchronous speed is 1500 RPM)

A change of speed up to 1498.18 RPM was achieved which can be rapidly modified till the desired value is attained. by changing value of mechanical load and rotor side " $R$ " and even the amount of time the resistor is active or ON.

This ensures to us that the mechanism delivers us the BELOW RATED SPEED control of an SRIM and can be used for all the high power devices very efficiently.

Coming to the efficiency of this method, we calculate it as follows:

\section{Output:}

$$
\begin{gathered}
\text { Po }=[(2 * \mathrm{pi} * \mathrm{~N} * \mathrm{~T}) / 60] \\
\text { Where, } \mathrm{N}=1498.18 \mathrm{RPM} \\
\mathrm{T}=9.376 \mathrm{~N}-\mathrm{m}
\end{gathered}
$$


Input:

The output power of the system is $\mathrm{Po}=1.470 \mathrm{~kW}$

$$
\begin{array}{r}
\mathrm{Pi}=\sqrt{ } 3 * \mathrm{~V} * \mathrm{I} * \cos \phi \\
\text { Where, } \mathrm{V}=400 \mathrm{~V} \\
\mathrm{I}=48 / \sqrt{ } 2 \mathrm{~A}=33.94 \mathrm{~A} \\
\operatorname{Cos} \phi=0.3
\end{array}
$$

The input power of the system is $\mathrm{Pi}=4.702 \mathrm{kw}$

EFFICIENCY:

Thus, $\eta=31.26 \%$

$$
\eta=[\text { output/input }] * 100
$$

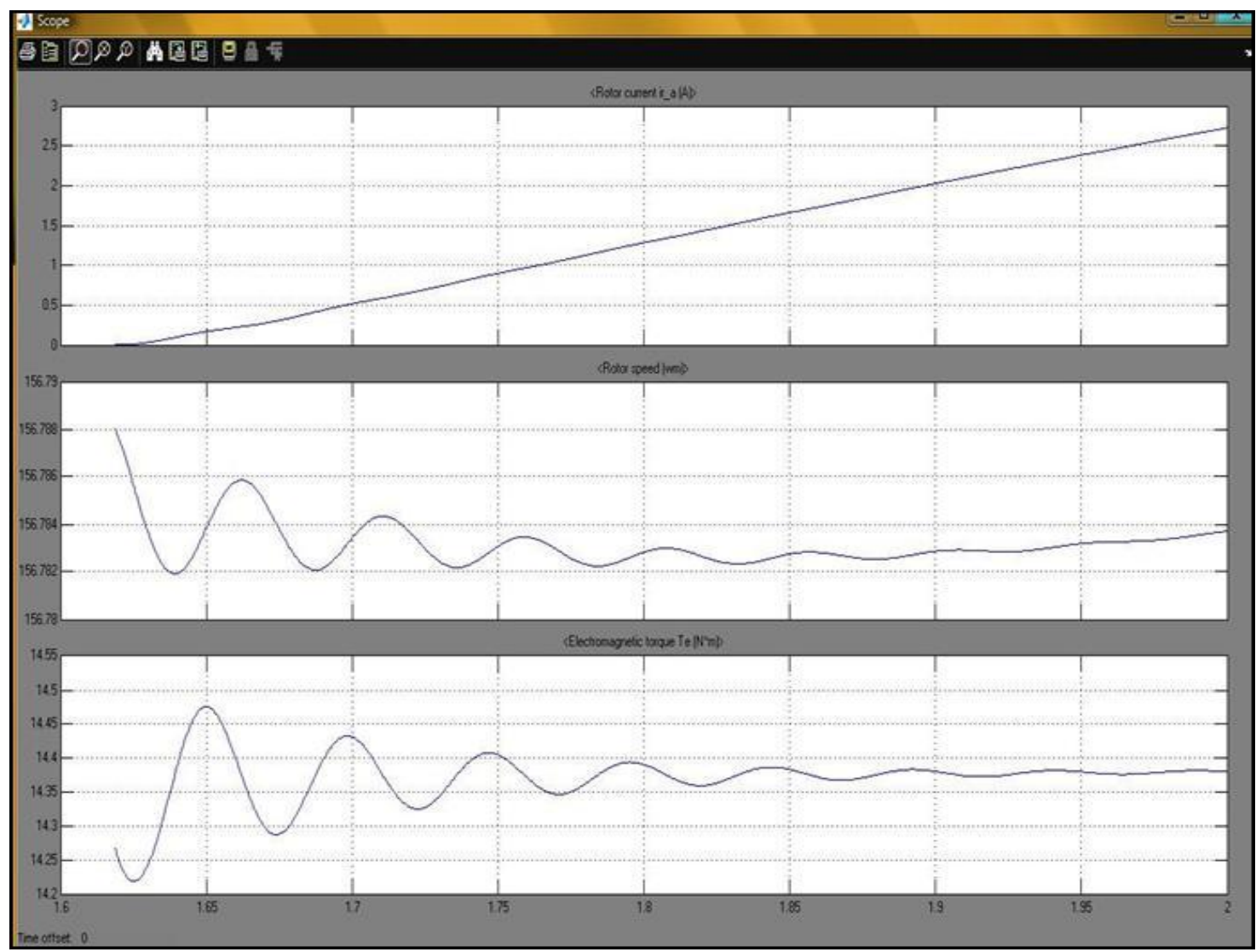

Fig: OUTPUT PLOT showing O/P TORQUE and SPEED of rotor

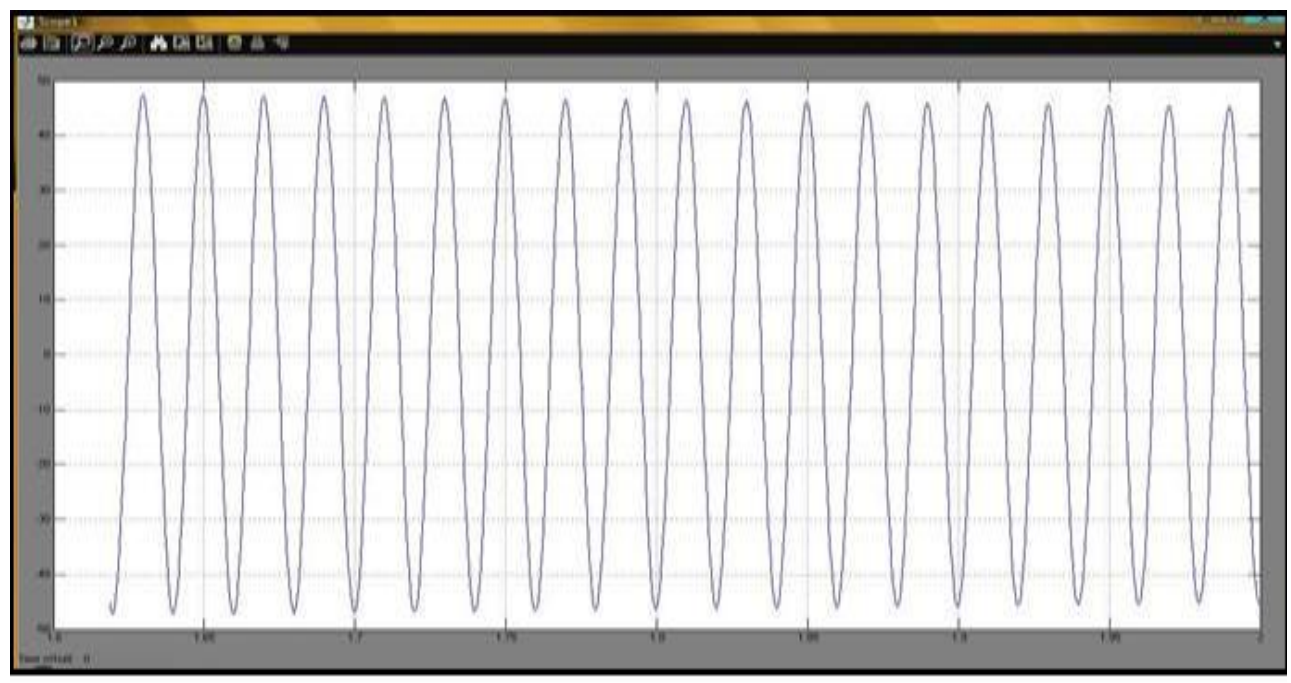

Fig: OUTPUT plot-I/P current of rotor 


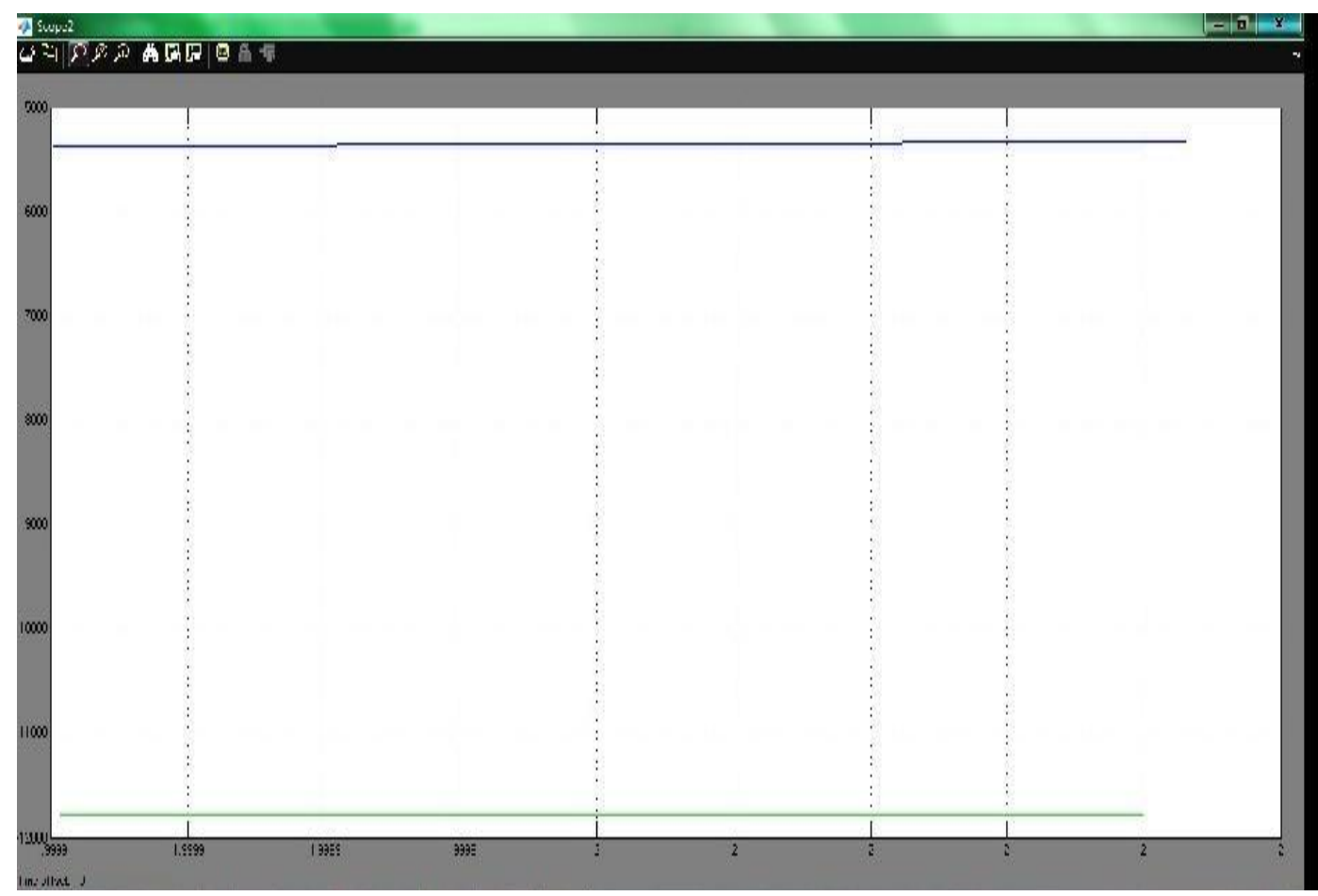

Fig: OUTPUT plot-Output power (active and reactive)

\section{Conclusion}

The construction of the present mechanism has been exclusively modified by designing a rotor side speed control drive which serves as a basis for the high power slip ring induction motors rotor side control. This is thus achieved by a single thyristor controlling the entire flow of rotor current suitably converted at the DC end being in parallel with the load resistance. This mechanism provides us the simplest technique of controlling the entire scheme via the turn on and turn off of the single load side thyristor and gives us the much required high current tolerance which is not possible and if possible not economically viable as in the case of the Insulated GATE bi polar transistors.

\section{Journal Papers:}

\section{References}

[1]. J. Kabouris and G. C. Contaxis, "Optimum expansion planning of an unconventional generation system operating in parallel with a large scale network," IEEE Trans. Energy Convers., vol. 6, no. 3, pp. 394-400, Sep. 1991.

[2]. P. Chiradeja and R. Ramakumar, "An approach to quantify the technical benefits of distributed generation," IEEE Trans. Energy Convers., vol. 19, no. 4, pp. 764-773, Dec. 2004

[3]. Y. H. Kim and S. S. Kim, "An electrical modeling and fuzzy logic controlof a fuel cell generation system," IEEE Trans. Energy Convers., vol. 14,no. 2, pp. 239-244, Jun. 1999.

[4]. K. N. Reddy and V. Agarwal, "Utility interactive hybrid distributed generation scheme with compensation feature," IEEE Trans. Energy Convers., vol. 22, no. 3, pp. 666-673, Sep. 2007.

[5]. K. S. Tam and S. Rahman, "System performance improvement provided by a power conditioning subsystem for central station photovoltaic fuel cell power plant," IEEE Trans. Energy Convers., vol. 3, no. 1, pp. 64-70.

[6]. R. Kyoungsoo and S. Rahman, "Two loop controller for maximizing performance of a grid-connected, photovoltaic fuel cell hybrid power plant," IEEE Trans. Energy Convers., vol. 13, no. 3, pp. 276-281, Sep. 1998.

[7]. F. Valenciaga and P. F. Puleston, "Supervisor control for a stand-alone hybrid generation system using wind and photovoltaic energy," IEEE Trans. Energy Convers., vol. 20, no. 2, pp. 398-405, Jun. 2005.

[8]. N. Kato, K. Kurozumi, N. Susuld, and S. Muroyama, "Hybrid powersupply system composed of photovoltaic and fuel-cell systems," in Telecommun. Energy Conf., Jpn, Oct., 2001, pp. 631-635.

[9]. T. Senjyu, T. Nakaji, K. Uezato, and T. Funabashi, "A hybrid power system using alternative energy facilities in isolated island," IEEE Trans. Energy Convers., vol. 20, no. 2, pp. 406-414, Jun. 2005.

[10]. Y. M. Chen, C. S. Cheng, and H. C.Wu, "Grid-connected hybrid PV/wind power generation system with improved dc bus voltage regulation strategy," in Proc. IEEE APEC, 2006, pp. 1089-1094.

[11]. G.Walker, "EvaluatingMPPT converter topologies using a MATLAB PV model," J. Electr. Electron. Eng., Aust. IE Aust., vol. 21, no. 1, pp. 49-56, 2001.

\section{Books:}

[12]. I.J.Nagarath, D.P.Kothari, Electrical Machines ( $4^{\text {th }}$ edition, Tata McGraw-Hill India, 2010).

[13]. Dr. P.S.Bhimbhra, Power Electronics ( $5^{\text {th }}$ edition, Khanna Publications India, 2012).

[14]. D. M. Mitchell, dc-dc Switching Regulator Analysis, (3rd ed. New York: McGraw-Hill, 1998). 